Territorialidade e sociobiodiversidade na configuração do espaço produtivo da Comunidade Olho d'Água dos Negros no município de Esperantina-PI

Elisângela Guimarães Moura Fé, Jaíra Maria Alcobaça Gomes

\title{
TERRITORIALIDADE E SOCIOBIODIVERSIDADE NA CONFIGURAÇÃO DO ESPAÇO PRODUTIVO DA COMUNIDADE OLHO D'ÁGUA DOS NEGROS NO MUNICÍPIO DE ESPERANTINA-PI
}

\section{Territoriality and sociobiodiversity in the productive area configuration of Olho d'água dos Negros Community in the city of Esperantina-PI}

\author{
Elisângela Guimarães Moura Fé \\ Universidade Federal do Piauí, Terezina, Piauí, Brasil \\ guimaraeselisangela@yahoo.com.br \\ Jaíra Maria Alcobaça Gomes \\ Universidade Federal do Piauí, Terezina, Piauí, Brasil \\ jaira@ufpi.edu.br
}

Artigo recebido em 27/04/2014 e aceito para publicação em 21/07/2015

RESUMO: O artigo apresenta reflexões que subsidiam a compreensão da relação entre os saberes locais e o manejo e uso de recursos naturais na organização do espaço produtivo da comunidade quilombola Olho d'Água dos Negros, situada no município de Esperantina, no Piauí. Buscou-se analisar a atual organização espacial, reunindo elementos socioeconômicos e simbólico-culturais, e a relação entre a sociobiodiversidade no extrativismo vegetal, com ênfase no buriti, na conservação ambiental e na valorização dos saberes locais. De caráter etnográfico e qualitativo, utilizou-se de mapeamento participativo para compreender os padrões de uso da terra. O processo de conquista da terra, aliado aos movimentos sociais, fortaleceu a identidade étnica e a mobilização política em busca de políticas públicas em prol de conquistas sociais na comunidade. Verificou-se que o espaço produtivo é limitado à produção de gêneros destinados ao autoconsumo, com reduzida atividade agrícola e subutilização de produtos oriundos do extrativismo de espécies vegetais. Os cercados, espaços de uso misto nos quintais das residências, é o tipo de uso que mais se expande na comunidade, na qual o buritizal cumpre a função ecológica de proteger o olho d'água e as veredas. Entretanto, no extrativismo, este fruto é subutilizado, sendo aproveitado apenas in natura. Palavras-Chave: Comunidade Quilombola. Territorialidade. Sociobiodiversidade. Uso da terra. Buriti.

ABSTRACT: This article presents reflections that grant the comprehension of the relation between the local knowledge and the handling and use of the natural resources in the organization of the productive areas of the Olho d'Água dos Negros, a Quilombola's community, located in the city of Esperantina in Piauí. The area organization was analyzed, assembling socioeconomic and cultural symbolic elements, and the relation between the sociobiodiversity in the vegetal extraction, with emphasis on Buruti (a local fruit), on the environment preservation and valorization of the local knowledge. About ethnography and qualitative aspects, participative mapping was used in order to understand the patters of the land use. The land conquest process, allied with social movements, strengthened the ethnic identity and the politic mobilization searching public policy in favor of social conquests for the community. It was seen that the productive area is limited to self-use production, with reduced agricultural activity and underuse of vegetal extraction 
products. The pound, assorted backyard area, is the kind of use that grows in the community, in which the "buritizal" (buriti cultivation), fulfils the ecological function of preserving olho d' água and its path. However, in the extraction, this fruit is underused, utilized just in natura.

Keywords: Quilombola. Community. Territoriality. Sociobiodiversit. Land Handling. Buriti.

\section{INTRODUÇÃ̃O}

O crescente interesse mundial pelo desenvolvimento científico e tecnológico decorrente de pesquisas sobre a biodiversidade tornou o Brasil reconhecido internacionalmente por sua grande diversidade biológica. Somada a esta diversidade, encontra-se uma pluralidade cultural materializada em povos e saberes tradicionais que, inseridos em vários ecossistemas brasileiros, com eles estabelecem relações próprias de uso e manejo de recursos naturais.

Compreende-se, com Diegues (2000), que as comunidades tradicionais estabelecem uma relação de simbiose entre a natureza, os ciclos naturais e os recursos naturais renováveis, com os quais se constrói um modo de vida baseado na elaboração de estratégias de uso e manejo, transferidos por oralidade, de geração a geração. Construídas historicamente, tais relações são adaptadas no acesso a novas técnicas e incorporam outros conhecimentos.

Esta pesquisa direcionou-se, no universo de grupos de povos tradicionais, às comunidades quilombolas. O conceito de quilombola utilizado segue a ótica de Schmitt, Turatti e Carvalho (2002), Almeida (2002), Arruti (2006) e Carril (2006), que analisam o termo sob a perspectiva da sociedade atual, respeitando o sentimento de pertencimento e de identidade étnica, mas com um olhar para as necessidades deste grupo na modernidade, tratando estas comunidades como parte das sociedades ditas tradicionais.

Ademais, a elevada endogenia, a baixa imigração, a territorialidade, a autoidentificação, a cooperação com a diversidade ecológica, tudo isso permeado por um conjunto de saberes que moldam o espaço, o sentimento de pertencimento ao lugar e as relações de parentesco, levam ao empoderamento e à organização espacial destas comunidades. Na verdade, os direitos que elas vêm conquistando, a partir da Constituição de 1988, despertaram discussões sobre a definição deste grupo social.

Território e territorialidade são conceitos diretamente ligados a estas questões, seja quanto à forma de organização espacial, seja no que concerne a políticas públicas que se estão delineando, no sentido de fortalecer o espaço produtivo destas comunidades ou regularizar a propriedade da terra, base de sua reprodução social. Estas políticas aparecem em resposta à articulação de movimentos sociais ou a demandas externas que pressionam o Estado em suas diferentes instâncias.

A apropriação coletiva da terra é característica da territorialidade de comunidades quilombolas. O'Dwyer (2010) traça algumas considerações quanto à territorialidade destes grupos, enfatizando que a ocupação da terra não se fez em termos de lotes individuais, predominando o uso comum, que obedece à sazonalização das atividades agrícolas, extrativistas ou não. Há, assim, diferentes formas de uso e ocupação da terra, que tomam por base laços de parentesco e vizinhança, assentados em relações de solidariedade e reciprocidade, porém vinculadas e articuladas a outras comunidades e a outros espaços.

As políticas concebidas sem o conhecimento das particularidades do lugar e do modo de vida das comunidades estão fadadas ao insucesso, por imporem uma nova realidade que dista de suas territorialidades e serem pouco operacionalizadas, em razão da burocracia no aparelho estatal. No Território dos Cocais (PI), foram registradas, pela Coordenação Estadual das Comunidades Quilombolas no Piauí, onze delas, que se veem envoltas por políticas públicas e projetos de geração de renda que, se teoricamente contribuiriam para a melhoria da qualidade de vida, apenas trouxeram ações pontuais, que não logram alterar a estrutura social. Desta forma, as comunidades com maior articulação política e mais empoderamento social são mais contempladas, enquanto um número muito grande continua quase invisível aos olhos do poder público.

Dentre estas políticas públicas, está o Plano Nacional de Promoção das Cadeias de Produtos da Sociobiodiversidade (PNPPSB), elaborado em 2007, pelo Ministério do Meio Ambiente (MMA), 
em parceria com o Ministério do Desenvolvimento Agrário (MDA) e Ministério do Desenvolvimento Social (MDS), e representantes da sociedade civil. O Plano tem como principal objetivo desenvolver ações integradas para a promoção e o fortalecimento das cadeias de produtos da sociobiodiversidade, pela agregação de valor e consolidação de mercados sustentáveis. Uma de suas diretrizes é aproveitar o manejo sustentável de áreas naturais por comunidades tradicionais para a efetivação de cadeias produtivas, visando à sua incorporação ao mercado.

Da inter-relação entre a diversidade biológica e a diversidade de sistemas socioculturais surge a sociobiodiversidade (PNPPSB, 2009), manifestada entre as comunidades tradicionais pela configuração do espaço produtivo e suas formas de uso da terra. Uma das atividades que melhor reflete esta sociobiodiversidade é o extrativismo vegetal.

Diegues (2003, p. 133) admite formas de extrativismo tradicional e moderno. Segundo ele, o extrativismo enquanto atividade econômica abarca a coleta, o manejo e até o cultivo das espécies, devido ao que lhe apresenta uma tipologia sintetizada em extrativismo de coleta, extrativismo manejado e extrativismo de cultivo.

Entretanto, utilizou-se, nesta pesquisa, apenas o primeiro como objeto de análise, por ser realizado por pequenos produtores ou comunidades rurais, e configura-se como uma prática social complementar à principal fonte de renda (DIEGUES, 2003, p. 134).

Nesta forma de extrativismo, usam-se os saberes construídos pelo modo de vida próprio do lugar, sendo pelo manejo tradicional que muitos produtos são explorados sazonalmente, respeitando-se o calendário natural das espécies vegetais. Entende-se que nestas condições, a conservação da biodiversidade pela atividade é compatível com a subsistência da população rural.

O PNPPSB priorizou, em 2009, o fortalecimento da cadeia produtiva do buriti no Estado do Piauí. Esta palmeira concentra-se em áreas de cerrado e em áreas de transição presentes no Território dos Cocais (CODEVASF/PLANAP, 2006).

Muitos municípios piauienses realizam a produção artesanal com a palha e a madeira, a exemplo de Boa Hora, onde o buriti é bastante empregado na produção artesanal, e Dom Expedito Lopes, onde se desenvolveu uma cadeia produtiva de doce de buriti. Em Ipiranga do Piauí, que tem como símbolo o buriti, há uma expressiva unidade fabril, que produz e comercializa o doce deste fruto pelo Estado.

No município de Palmeira do Piauí, localizado a sudoeste do Estado, a Natura Cosméticos executou um projeto de conservação e uso sustentável da biodiversidade do buriti, que propôs o desenvolvimento local e a repartição de benefícios não monetários em contrapartida ao acesso ao patrimônio genético e ao conhecimento tradicional associado ao óleo de buriti (MATA, 2010).

Teve, pois, este estudo, o objetivo de compreender a configuração espacial, a sociobiodiversidade e a territorialidade em uma comunidade quilombola. Buscou-se analisar a atual organização espacial, reunindo elementos socioeconômicos e simbólico-culturais para a compreensão do processo de conquista e uso da terra, com ênfase no extrativismo do buriti e sua relação com os saberes locais e a com a conservação ambiental. A área de pesquisa foi a comunidade Olho d'Água dos Negros, situada na zona rural do município de Esperantina (Figura 1). Esta pesquisa é fruto do Projeto Roda de Cultura, uma parceria entre a Universidade Federal do Piauí (UFPI) e a Università Degli Studi di Verona, e foi realizada no período de 2010 a 2013. 
Figura 1 - Localização da comunidade Quilombola Olho d’Água dos Negros, Esperantina, Piauí, Brasil.

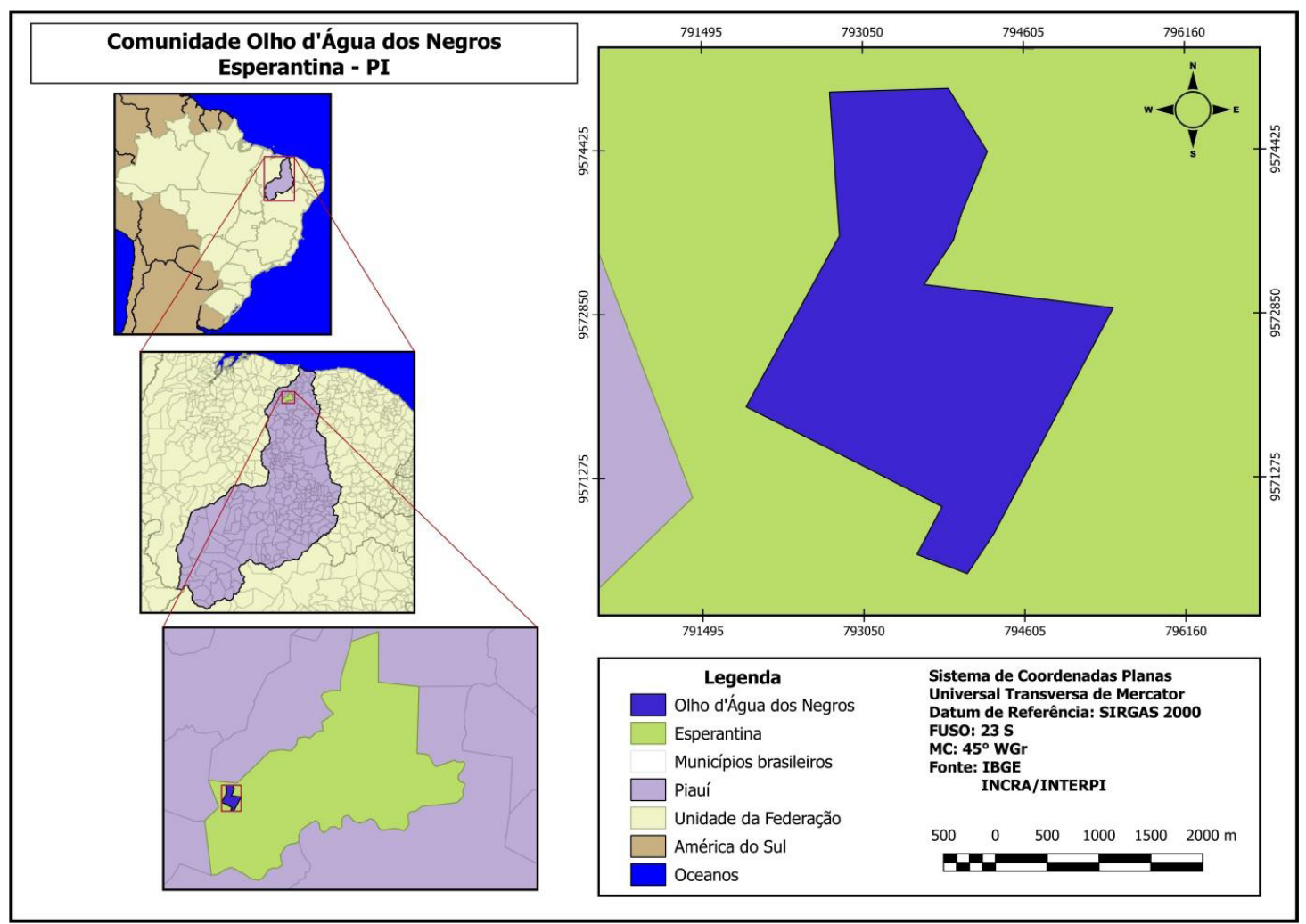

Fonte: Elaboração Elisângela Guimarães Moura Fé (2013).

A comunidade está inserida em uma área de transição, apresentando fisionomia de cerrado, intercalada por palmeiras de babaçu e por brejos.

Por meio de oficinas realizadas pelo Projeto Roda de Cultura, identificaram-se, em seu meio ecológico, áreas de brejos com ocorrência de buriti, um produto da sociobiodiversidade. Além disto, foram realizadas entrevistas qualitativas semiestruturadas com o Grupo Colhendo Frutos e Gerando Vida, composto por nove mulheres.

Para a compreensão da organização espacial e do padrão de uso das terras, utilizam-se oficinas de mapeamento participativo e as técnicas de sensoriamento remoto. Inicialmente, foram identificados, por membros da comunidade, os pontos-limite, a partir de estacas por eles fincadas e chamadas, localmente, de variantes, que foram posteriormente conferidos com os dados do INCRA/ INTERPI e trabalhos de campo.

As estratégias de investigação basearam-se na observação participativa das práticas cotidianas do grupo, com o intuito de captar os elementos individuais e coletivos de conhecimento sobre o ambiente natural. Entre os meses de outubro e novembro de 2013, observaram-se as práticas de manejo do buriti.

\section{Territorialidade, identidade étnica e a conquista da terra}

A análise histórica da formação territorial não se concebeu como uma retrospectiva do passado, mas como um meio de entender a atual organização espacial da comunidade. O espaço é delimitado pelas relações de poder (SOUZA, 2003), e este é definido, sempre com raízes sociais, por relações, ações, fatos, dominação e influência (CLAVAL, 2007).

Desta relação temporal e complexa entre os grupos sociais e o seu ambiente surge a territorialidade (SOUZA, 2003). Esta é, por sua vez, fruto da 
territorialização do espaço que aparece no processo de apropriação social de sua parcela, sendo vivida e apreendida por uma identidade espacial construída nas relações sociais, regras e normas do meio natural, do trabalho, das técnicas e tecnologias e dos conflitos historicamente determinados (SAQUET, 2011).

Segundo Santos (2008, p. 33), admitese que a acumulação do tempo histórico permite compreender a atual organização espacial, pois cada lugar é uma fração do espaço total onde se exercem as relações sociais em um dado momento. Neste sentido, o processo histórico de formação territorial da comunidade Olho d'Água dos Negros representa uma amostra do processo de colonização e povoamento do território piauiense no município de Esperantina, o qual se caracterizou pelo estabelecimento de fazendas de criação gado de forma extensiva em grandes extensões de terra.

A colonização do território piauiense pelos portugueses fez-se prioritariamente pelo sistema de sesmarias, dando origem a grandes latifúndios. O processo de formação do município de Esperantina inicia-se em 1739, quando foram concedidas terras do sítio Boa Esperança ao baiano Miguel de Carvalho e Silva, que tinha uma fazenda de gado vacum no local onde se fixou e gerou descendente (FERREIRA, 2008). A Fazenda Olho d'Água surge, conforme Ferreira (2008), neste processo:

Em 1847, nas terras da sesmaria Boa Esperança, foi fundada a fazenda Olho d'Água, por Mariano de Carvalho Castelo Branco. A implantação da fazenda representava uma caracterização do espaço produtivo do Piauí a partir da implantação da pecuária. A fazenda da Boa Esperança, nas testadas do sítio (fazenda) Tranqueira seguia na parte direita do rio Longá, rio acima, até lindar com a antiga fazenda Taquary, até chegar onde hoje se encontra a divisa com o atual município de Matias Olímpio, depois do sítio (fazenda) conhecida hoje (2006) como Olho d'Água dos Negros [...]. (FERREIRA, 2008, p.24).

Por volta do ano de 1900, perfura-se na fazenda uma cacimba, que se torna jorrante, passando a chamar- se Olho d'Água dos Pires. Na década de 1980, com o falecimento do proprietário, a Fazenda Olho d'Água dos Pires transfere-se, por herança, a seus filhos (EMATER, 2008).

De acordo com entrevistas com membros da Associação de Desenvolvimento Comunitário dos Pequenos Produtores da Comunidade Olho d' Água dos Negros (ADECOPOL), neste período, a população local submetia-se a trabalhar nas terras da fazenda para garantir sua moradia e utilizava a terra para uso agrícola e extrativo, já que a mesma era arrendada e os gêneros produzidos só poderiam ser vendidos aos proprietários. Há relatos de que houve maus tratos aos moradores que, ao final da década, começaram a oferecer resistências e a se articularem politicamente para findar tal situação.

Na década de 1990, os moradores da Fazenda Olho d'Água dos Pires enfrentaram um momento de conflito em função da venda das terras. Conforme entrevista com membros da ADECOPOL, o novo proprietário impediu a população local de ter acesso aos recursos do meio ecológico no entorno da fazenda e ao espaço de lazer. Neste período, os objetos e formas espaciais que simbolizavam a história da referida fazenda foram sendo gradualmente destruídos.

Em 1993, os moradores da Fazenda Olho d'Água dos Pires construíram uma casa para sediar reuniões e articular meios de conquistar as terras onde viviam, a qual foi incendiada, a mando do proprietário. Em 1994, as reuniões e manifestações religiosas e culturais fortaleceram-se e passaram a ser realizadas sob uma árvore, local onde posteriormente foi construída a atual capela. Em 1998, fundou-se a Associação de Desenvolvimento Comunitário dos Pequenos Produtores da Comunidade Olho d' Água dos Negros (ADECOPOL), quando passaram a ter maior organização social e política.

Em 2002, os moradores organizaram-se politicamente, através da referida associação, apoiados pelo Sindicato de Trabalhadores Rurais de EsperantinaPI(STRE), Centro de Educação Popular Esperantinense (CEPES) e Igreja Católica, e mobilizaram-se para adquirir as terras da Fazenda Olho d'Água dos Pires. Em 2004, a Prefeitura Municipal de Esperantina a entregou, por meio de Contrato de Comodato, com prazo indeterminado, à ADECOPOL. O fato fortaleceu a organização política e social da população que, em 2005, modificou o nome da 
propriedade para Olho d'Água dos Negros, toponímia que expressa o sentimento de pertencimento ao lugar.

Assegurados pelo Decreto 4.887/2003, que regulamenta o artigo 68 do Ato das Disposições Constitucionais Transitórias (ADCT), iniciaram um processo de reconhecimento de titulação da comunidade afrodescendente. Em 2005, receberam o certificado de Comunidade Quilombola, emitido pela Fundação Cultural Palmares, e em 2006, o título de propriedade da terra, expedido pelo INCRA/INTERPI.

$\mathrm{O}$ novo qualificativo reafirmou o compromisso político da comunidade contra a indiferença e o preconceito. A importância da conquista da terra é evidenciada no discurso da população residente, conforme relatos colhidos em entrevistas. Para C. H. S, 42 anos, que liderou o processo de conquista da terra,

Graças a Deus, aqui, o que nós produzimos na roça é nosso e não temos que pagar renda para ninguém. Hoje, em comparação com uns vinte anos atrás, estamos no nosso lar. Tudo isso foi conseguido através de luta e organização social apoiada por movimentos sociais, porque são eles, junto com as comunidades, as bases que pressionam para fazer a política de governo funcionar a favor de uma vida mais digna (Informação verbal. C. H. S. 42 anos. Depoimento de representante da ADECOPOL em oficina realizada pelo Projeto Roda de Culturas - 2012).

Verifica-se o reconhecimento da participação de movimentos sociais e a importância de políticas públicas nas comunidades locais e da identidade socioespacial reforçada pela conquista da terra. As relações de poder, delimitadas no espaço e na ação dos agentes políticos produtores, articuladas com a força da identidade étnico-espacial da população local, permitiram a transformação de uma propriedade privada em lugar de uso coletivo de terras, a comunidade quilombola Olho d'Água dos Negros.

\section{Configuração espacial das atividades produtivas}

O espaço produtivo da comunidade Olho d'Água dos Negros não apresenta muita complexidade. Organiza-se em torno de atividades primárias de autoconsumo, predominando a agricultura familiar, o extrativismo vegetal e a pequena criação de animais, com poucos impactos econômicos e ambientais. As relações de trabalho na terra são marcadas pelo parentesco, por meio de uma mão de obra familiar, já que, segundo Claval (2007), nesse nível mais simples de organização produtiva recai sobre a família a responsabilidade de produzir o necessário e designar o devido a cada um.

Na Figura 2 está representado por pontos, linhas e polígonos, o espaço produtivo da comunidade, identificando-se os padrões de localização dos objetos espaciais de referência cultural. Nesta figura, é possível verificar a presença de duas comunidades dentro do território Olho d'Água dos Negros, a Coité e a Cajueiro, que não são reconhecidas como quilombolas, embora se tenham estabelecido nas áreas antes do processo de titulação das terras e ali permanecem sem registros de conflitos fundiários.

A organização do espaço agrícola caracterizase pela plantação de gêneros que compõem parte da alimentação diária dos membros da comunidade. As culturas de sequeiro, como feijão, arroz, milho, e em menor escala, a mandioca, são predominantes, e as roças, conforme a Figura 2, estão localizadas entre os morros, destinados a áreas de conservação. As roças ficam em áreas com cotas altimétricas entre 95 e 115 metros, sendo chamadas, localmente, de baixões.

Devido à propriedade coletiva das terras, cada família pode dispor de até dois hectares para roças. Selecionam a área de plantio, conforme a coloração e a textura do solo: quanto mais escuro e menos pedregoso, melhor; é reduzida a degradação dos solos (figura 2), pois há poucas áreas com solo exposto; não é comum a utilização de agrotóxicos nas lavouras, já que utilizam, na conservação dos solos, o próprio material vegetal extraído durante a limpeza do terreno, chamado, localmente, de retirana.

Nas áreas de altitudes mais elevadas, as plantações são realizadas nos quintais das residências, caracterizando um espaço de uso misto chamado, localmente, de cercados (figura 2), nos quais as famílias se dedicam à plantação, em especial, de espécies frutíferas, como a goiaba, a manga, o limão, a laranja, a acerola e o caju. 
Territorialidade e sociobiodiversidade na configuração do espaço produtivo da Comunidade Olho d'Água dos Negros no município de Esperantina-PI Elisângela Guimarães Moura Fé, Jaíra Maria Alcobaça Gomes

Figura 2 - Mapa de uso da terra da comunidade Olho d'Água dos Negros.

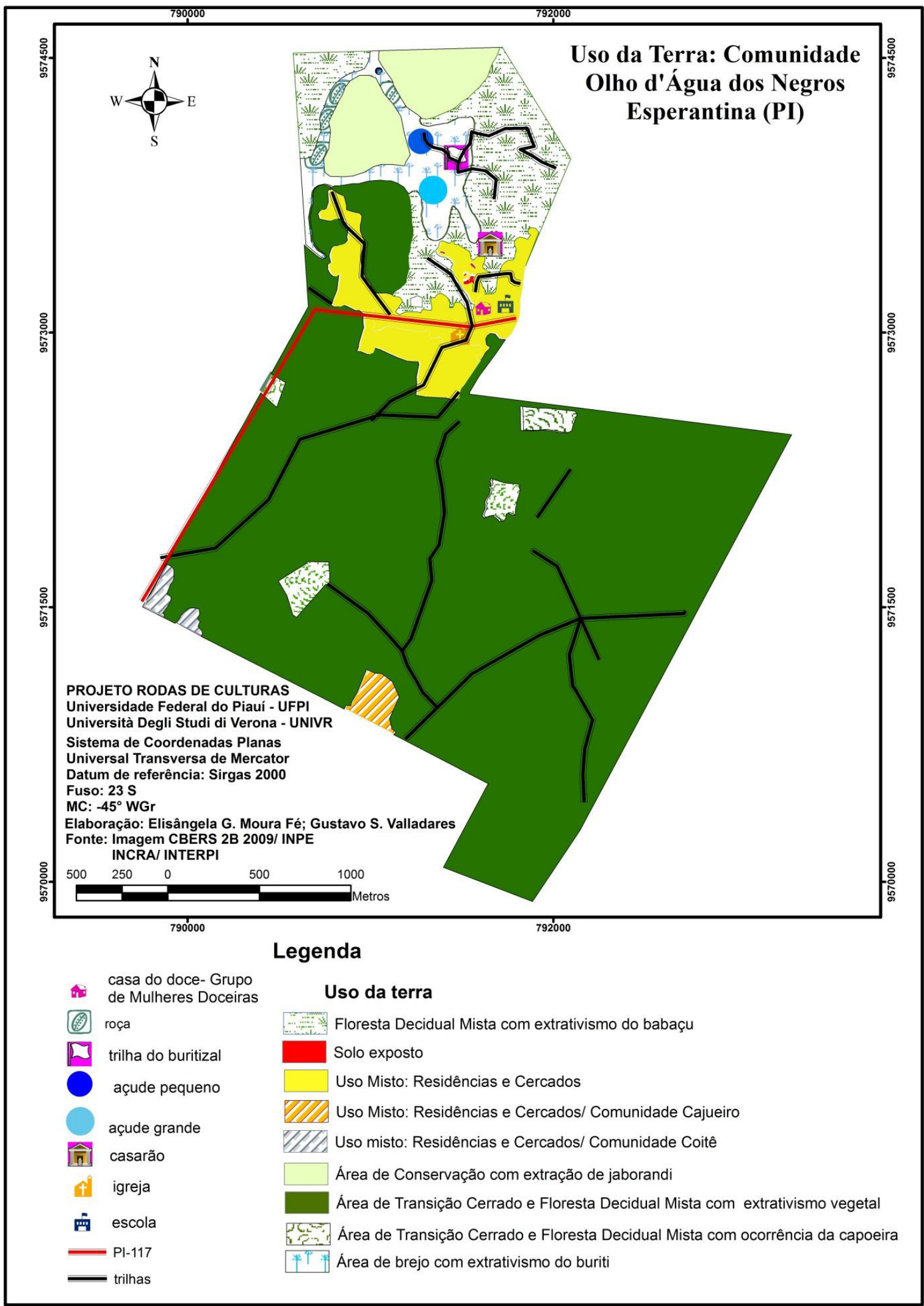

Fonte: Elaboração Elisângela G. Moura Fé; Gustavo S. Valladares.

Soc. \& Nat., Uberlândia, 27 (2): 297-308, mai/ago/2015 
Os cercados são o tipo de uso da terra que mais se tem expandido na comunidade Olho d'Água dos Negros, em função da redução das áreas de roça. Os fatores que contribuem para isso são: a redução da mão de obra masculina local, que busca nas cidades melhores oportunidades de trabalho e renda; o sustento básico das famílias, que dependia especialmente dos alimentos produzidos na roça e está sendo substituído pela renda proveniente do Programa Bolsa Família e das aposentadorias dos idosos; o acesso à escola também provocou tal redução; sem falar da baixa produtividade e dos preços de mercado, que desestimularam a produção de excedente agrícola.

Inserida em um meio ecológico de transição do cerrado para a floresta decidual mista (Figura 2), a paisagem vegetal da comunidade Olho d'Água dos Negros fornece um grande potencial extrativista, especialmente para os Produtos Florestais Não Madeireiros (PFNMs). Os babaçuais marcam a fisionomia da paisagem e a extração do coco babaçu, praticado em todo o Território dos Cocais (PI), que é realizada por mulheres que adentram as matas e fazem a derrubada e a quebra deste coco.

Estas mulheres encontram no Movimento Interestadual das Quebradeiras de Coco Babaçu (MIQCB) apoio para a extração e comercialização deste produto. As mulheres associadas ao MIQCB comercializam o excedente da produção no sistema de cantina e repassam o produto para uma das líderes locais do Movimento, que efetua a venda, na sede do município de Esperantina, a preço vigente no mercado.

Outro importante produto do extrativismo vegetal é o jaborandi, que vem despertando o interesse de empresas que o utilizam na produção de cosméticos e medicamentos. Na comunidade, a espécie é extraída em áreas de conservação local (figura 2), por um grupo de pessoas cadastradas pelo Projeto Valorização do Jaborandi, que se tornou um elo entre a comunidade e o mercado de PFNM. O manejo do jaborandi é assim descrito por um dos membros do grupo: "o período de coleta do jaborandi é entre os meses de agosto a outubro. A planta selecionada para o corte deve ter em média 50 $\mathrm{cm}$ de altura. Depois de trinta dias, a planta cortada já está com 15 a 20 centímetros de altura".

Além do babaçu e do jaborandi, a comunidade conta com o extrativismo de espécies típicas do cerrado, como o pequi, o bacuri e o buriti. Este recebeu uma atenção especial nesta pesquisa, em função da proposta PNPPSB de valorização de sua cadeia produtiva em comunidades locais do Piauí.

\section{Sociobiodiversidade no extrativismo do buriti (mauritia flexuosa l.f)}

O buritizal é uma formação de cerrado que surge em solos úmidos, argilosos ou arenosos e ácidos. Pode ser encontrada em igapós, beira de rios e de igarapés e, por ser uma comunidade hidrófila, localizase, com mais frequência, em depressões onde a água está concentrada, formando uma vegetação das veredas (LORENZI 2010; RIZINNI, 1979; POTT, 2004). A vereda é formada pelo campo limpo e pelo brejo.

O buriti nasce principalmente dentro dos brejos, áreas que beiram os cursos d'água onde o solo é sempre encharcado, podendo ser encontrado em locais mais alagados dos campos limpos (SAMPAIO, 2011). Os solos das veredas são hidromórficos, turfosos, saturados deágua durante a maior parte do ano, atuam como filtros, removendo sedimentos e nutrientes, e fornecendo água limpa para os habitats a jusante (POTT, 2004).

Por serem ambientes vulneráveis a alterações, as zonas úmidas e veredas são reconhecidas como Áreas de Preservação Permanente (APP). Na Resolução ${ }^{\circ}$ 303, de 20 de março de 2002, do Conselho Nacional do Meio Ambiente (CONAMA), que dispõe sobre parâmetros, definições e limites de APP, os $\S 2^{\circ}$ e $3^{\circ}$ do art. 3 consideram como APP as nascentes ou olhos d'água locais onde afloram naturalmente, mesmo que de forma intermitente, a água subterrânea e a vereda. Trata-se de espaço brejoso ou encharcado que estão presentes nascentes ou cabeceiras de cursos d'água onde ocorrem solos hidromórficos, com o predomínio de buritis do brejo (Mauritia flexuosa L. f.) e outras formas de vegetação típica.

O buriti, quanto ao âmbito econômico, encontra valor tanto como bem de uso direto quanto no mercado de serviços ambientais. No uso direto, oferece um conjunto de opções de produção e comercialização, e nos serviços ambientais, contribui para a conservação das veredas, dos recursos hídricos e dos ecossistemas. $\mathrm{Na}$ verdade, da palmeira do buriti aproveita-se tudo, da raiz às folhas, usando-se a mesma no artesanato, na 
alimentação, nas indústrias cosmética e farmacêutica, e na ornamentação, destacando-se como um relevante produto da sociobiodiversidade brasileira.

$\mathrm{Na}$ comunidade Olho d'Água dos Negros, a safra de buriti vai do final de setembro ao término de novembro, período seco e de elevadas temperaturas. $\mathrm{O}$ início da coleta e a forma de repartição dos frutos são acertadas em reunião da ADECOPOL com as famílias residentes na comunidade.

Para realizar o trabalho de corte e derrubada do buriti, contrata-se um trabalhador geralmente vindo das populações vizinhas, devido à dificuldade de encontrar quem esteja disponível a isso na própria comunidade. Os objetos técnicos utilizados no corte do buriti são uma vara de bambu, além de facões e cestos, sacos e latas. Munidas destes objetos, as mulheres, grupo que lidera a extração do buriti na comunidade, segue pelas trilhas pré-existentes acompanhadas muitas vezes dos filhos, em direção ao brejo.

O corte do buriti é um processo que despende de esforço físico e habilidade do trabalhador. Como não é costume local subir na palmeira para extrair os frutos, o corte é feito sem o uso de equipamentos de segurança. Após a derrubada do fruto, as mulheres iniciam a coleta e, em seguida, separam os melhores para o processamento, sendo os demais aproveitados na alimentação de animais criados nos cercados de suas casas.

As mulheres coletoras afirmaram nas entrevistas que o fruto do buriti colhido no chão, sem o corte, é o de melhor qualidade. Porém, como o brejo não é cercado, os animais o consomem, inviabilizando uma coleta em maior escala. Passados cerca de três dias, as mulheres reúnem-se na Casa do Doce e iniciam o processamento. Com uma divisão simples de tarefas, descascam o buriti para a extração da massa e o passam em uma peneira, que chamam de arupempa.

Em oficinas realizadas durante o Projeto Roda de Cultura, estas mulheres discutiram as suas expectativas e as práticas produtivas, revelando o desejo de conhecer mais sobre o aproveitamento dos produtos do extrativismo em outros elos de produção, como o artesanato. Segundo elas, a Casa do Doce foi construída em razão do desperdício de frutas da estação, mas sentem a necessidade de melhorar e aumentar a produção, que carece de mais infraestrutura, aperfeiçoamento do trabalho e melhores condições de escoamento para o mercado regional. A Figura 3 sintetiza as etapas da cadeia do buriti na comunidade Olho d'Água dos Negros:

Figura 3 - Etapas da cadeia produtiva do buriti na comunidade Olho d'Água dos Negros

\begin{tabular}{|c|l|l|}
\hline \multicolumn{1}{|c|}{ Etapas } & \multicolumn{1}{|c|}{ Descrição } & Dimensão temporal \\
\hline $\begin{array}{l}\text { Colheita dos } \\
\text { frutos do buriti }\end{array}$ & $\begin{array}{l}\text { Antes do início da safra, as mulheres coletoras verificam o processo de } \\
\text { amadurecimento do buriti, que é extraído da palmeira por meio do corte dos cachos. } \\
\text { A coleta dos frutos é realizada até duas vezes no período da safra. A quantidade é } \\
\text { proporcional à repartição dos frutos pelos coletores e o suficiente para o trabalho de } \\
\text { um dia no grupo de mulheres doceiras. }\end{array}$ & Semanal \\
\hline Processamento & $\begin{array}{l}\text { Realizado na Casa do Doce. O buriti permanece dois dias de molho. Retira-se a crosta } \\
\text { e procede-se à raspa do fruto para extrair a massa. Com a massa, produzem o doce e a } \\
\text { polpa, que ficam armazenados nas casas das mulheres, porque não há infraestrutura na } \\
\text { Casa do Doce. Não há aproveitamento da palha, do talo e da fibra do buriti. }\end{array}$ & Dias \\
\hline Comercialização & $\begin{array}{l}\text { O doce e a polpa do buriti são comercializados em feiras realizadas semanalmente } \\
\text { no município de Esperantina e São João do Arraial. Os produtos já têm clientela fiel, } \\
\text { sendo também vendidos nas casas de moradores que já compravam gêneros agrícolas } \\
\text { dos pais destas mulheres, em tempos passados. }\end{array}$ & Semanal \\
\hline
\end{tabular}

Fonte: Etapas baseadas em SAMPAIO (2011). Pesquisa direta (out. /2012). 
Segundo Castro (2000), embora existam representações simbólicas e místicas que perpassam diferentes formas de organizar o trabalho, cada uma delas defronta-se com as capacidades e os limites de saberes e interesses de cada grupo, suas formas de agir sobre o território e de apropriar-se dos recursos sob os padrões específicos de seletividade. O grupo produz uma diversidade de doces com frutas nativas, especialmente o buriti e outras plantadas nos cercados de suas casas. A produção é comercializada aos finais de semana, em feiras livres no município e arredores, onde já contam com um pequeno mercado de compradores que demandam e reconhecem a qualidade do produto.

O momento do processamento do buriti na Casa do Doce é muito significativo, visto que o local se torna palco de encontro de crianças, jovens, idosos, homens e mulheres que, unidos por laços de parentesco, são atraídos pelo momento que vivenciam, tornando-se coadjuvantes do processo por meio do qual resgatam a memória individual e coletiva, recontando histórias e, principalmente, as experiências por que passam no cotidiano da comunidade, compreendida pelos que compartilham a mesma identidade.

\section{CONSIDERAÇÕES FINAIS}

Para a compreensão acerca da organização do espaço produtivo na comunidade Olho d' Água dos Negros, consideramos o espaço como um agrupamento de elementos de diferentes tempos que sintetiza, de um lado, a evolução da sociedade, e explica, de outro, situações na atualidade. Neste sentido, algumas conclusões da pesquisa revelam que o modelo de desenvolvimento baseado na dependência da comunidade quanto aos ciclos da natureza, com baixo emprego de tecnologia, forma um espaço produtivo pouco dinâmico, caracterizado por atividades voltadas para o autoconsumo, que não provocam muitas alterações em seu padrão de organização espacial.

A organização espacial da comunidade Olho d’Água dos Negros apresenta objetos espaciais que simbolizam a história colonial de escravidão, e em um passado menos distante, reflete a história de dependência da população deste lugar em relação ao proprietário da terra, e o momento de ruptura a partir da organização social da população local apoiada pelos movimentos sociais pela conquista da terra, revelando e fortalecendo a sua identidade étnicoespacial.

O extrativismo do buriti requer a elaboração, a execução e o monitoramento de planos de manejo que ampliem e conservem as áreas de buritizais nos brejos. O fortalecimento da cadeia produtiva do buriti na comunidade Olho d'Água dos Negros demanda que sejam removidos entraves, como a viabilização da infraestrutura de produção na unidade produtiva, que necessita de equipamentos necessários ao processamento.

A reprodução, de geração para geração, das práticas de manejos dos recursos naturais, é fruto do modo de vida local, concebido a partir da observação do saber fazer, o que exige um equilíbrio no sentido de atender a uma demanda que garanta aos pertencentes da comunidade Olho d'Água dos Negros renda justa e evite a devastação dos buritizais.

\section{REFERÊNCIAS}

ALMEIDA, A. W. B. de. Os quilombos e as novas etnias. In: E. C. O’Dwyer. Quilombos: identidade étnica e territorialidade. São Paulo: ABA/FGV, 2002. Disponível em: <http://www.abant.org.br/conteudo/ livros/Quilombos.pdf>. Acesso em: 1 mai. 2013.

ARRUTI, J. M. A. Emergência dos "remanescentes": Notas para o diálogo entre indígenas e quilombolas. Artigo disponível em: <http://www.scielo.br/ pdf/mana/v3n2/2439.pdf $>$. Acesso em: 15 abr. 2013. DOI:http:dx.doi.org/10.1590/S010493131997000200001

BRASIL. Ministério do Meio Ambiente - MMA. Resolução $n^{\circ} 303$, de 20 de março de 2002. Dispõe sobre parâmetros, definições e limites de Áreas de Preservação Permanente. Disponível em: < http:// www.mma.gov.br/port/conama/res/res02/res30302. html> Acesso em: 15 ago. 2013. 
BRASIL. Ministério do Meio Ambiente - MMA. Plano Nacional de Promoção de Cadeias de Produtos da Sociobiodiversidade. Plano de ação 2009. MDA; MMA; MDS. Brasília (DF), 2009. Disponível em: $<$ http://www.mda.gov.br/sitemda/sites/sitemda/ files/user_arquivos_64/PLANO_NACIONAL_DA_ SOCIOBIODIVERSIDADE-julho-2009.pdf > Acesso em: 7 abr. 2013.

CARRIL. L. de F. B. Quilombo, território e geografia. São Paulo: Revista Agrária, n. 3, p. 156-171, 2006. Disponível em: <http://www.geografia.fflch.usp.br/ revistaagraria/revistas/3/8_carril.pdf $>$ Acesso em: 20 mar. 2013. DOI: http://dx.doi.org/10.11606/issn.18081150.v0i3p156-171

CASTRO, E. Território, biodiversidade e saberes de populações tradicionais. In: Etnoconservação: novos rumos para a conservação da natureza. São Paulo: Hucitec, Núcleo de Apoio à Pesquisa sobre Populações Humanas e Áreas Úmidas Brasileiras, USP, 2000. p. 165-180.

CLAVAL, P. A geografia cultural. Trad. Luiz Fagazzola Pimenta e Margareth de Castro Afeche Pimenta. 3 ed. Florianópolis: UFSC, 2007. 453 p.

CODEVASF. Companhia de Desenvolvimento dos Vales dos Rios São Francisco e do Parnaíba. PLANAP: Plano de Ação para o Desenvolvimento Integrado da Bacia do Parnaíba: Livro 2 - Síntese Executiva Território dos Cocais, 2006.

DIEGUES, A. C. (b). O mito da natureza intocada. São Paulo: Hucitec, Núcleo de Apoio à Pesquisa sobre Populações Humanas e Áreas Úmidas Brasileiras, USP, 2000. 169 p.

DIEGUES, A. C. Aspectos sociais e culturais do uso dos recursos florestais da Mata Atlântica. In: Sustentável Mata Atlântica: exploração de seus recursos florestais. São Paulo: Editora SENAC, 2003. p. 133-154.

EMATER. Plano de desenvolvimento sustentável da comunidade negra rural quilombola Olho d'água dos Negros. Projeto Ater no Quilombo. Esperantina: EMATER / MDA / nº 056/2007 / meta 18.2008.

FERREIRA, E. P. A mistica do parentesco. São Paulo: Livraria Correia Lago, 1993. v. 3.

INCRA. Relatório técnico de identificação e delimitação: comunidade Olho d' Água dos Negros. Data Coité Esperantina - PI. Projeto de regularização fundiária - comunidades negras rurais quilombolas do Estado do Piauí. Processo INCRA n ${ }^{\circ}$ 54380.001033/2004-19, 2005.

LORENZI, H. et al. Palmeiras no Brasil-nativas e exóticas. Nova Odessa, SP: Instituto Plantarum, 1996.

MATA, P. Conhecimento tradicional, biodiversidade e repartição de beneficios: o caso dos produtores de óleo de buriti de Palmeira do Piauí. Disponível em: $<$ http://ojs.c3sl.ufpr.br/ojs2/index.php/campos/article/ viewFile/21047/17357>. Acesso em: 2 mar. 2013. DOI: http://dx.doi.org/10.5380/cam.v11i2.21047

O'DWYER. Eliane Cantarino. Terras de Quilombo no Brasil: direitos territoriais em construção. In: ALMEIDA, A. W. B. de (Orgs.) et al. Cadernos de Debates Nova Cartografia Social: territórios quilombolas e conflitos. Manaus: Projeto Nova Cartografia Social da Amazônia/ UEA Edições, 2010. p. $42-49$.

POTT, V.J.; POTT, A. Buriti - Mauritiaflexuosa. Fauna e Flora do Cerrado. Campo Grande: 2004. Disponível em: <http://www.cnpgc.embrapa.br/ rodiney/series/ buriti/buriti.htm>. Acesso em: 19 jan. de 2012.

RAfFestin. C. Por uma Geografia do Poder. Tradução Maria Cecília França. São Paulo: Ática, 1993. (Série: Geografia e Política. v. 29).

RIZZINI, C.T. Tratado de Fitogeografia do Brasil. São Paulo: Hucitec, 1979.

SCHMITT, A; TURATTI, M. C. M.; CARVALHO, M. C. P. de. A atualização do conceito de quilombo: 
identidade e território nas definições teóricas. Ambiente. soc., Campinas, n. 10, jun. 2002. Disponível em: < http://www.scielo.br/pdf/asoc/n10/16889. pdf $>$. Acesso em: 17 mai. 2013. DOI: http:dx.doi. org/10.1590/S1414-753X2002000100008

SAMPAIO, M.B.; SCHMIDT, I. B.; FIGUEIREDO, I. B. Harvesting effects and population ecology of the buriti palm (Mauritia flexuosa L. f., Arecaceae) in the Jalapão region, Central Brazil. Economic Botany, v. 62 , n. 2 , p. 171-181, 2008. DOI: 10.1007/s12231008-9017-8

SANTOS. M. (a). Espaço e Método. São Paulo: EDUSP, 2008. 118 p.

SAQUET, M. A. Por uma geografia das territorialidades e das temporalidades: uma concepção multidimensional voltada para a cooperação e para o desenvolvimento territorial. São Paulo: Outras Expressões, 2011. 128 p.

SOUZA, M. J. L. de. O território: sobre espaço e poder, autonomia e desenvolvimento. In: CASTRO, I. E. C. Geografia: conceito e temas. Rio de Janeiro: Bertrand Brasil, 2003. p.77-116. 